\title{
The Effect of Thickness of Covering Soil on Soil Water Retention and Crop Growth in Land Reclamation Filled with Fly Ash: Evidence from GPR and UAV Investigation
}

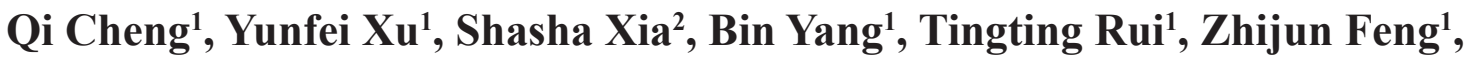 \\ Yang Wang', Shiwen Zhang ${ }^{2 *}$, Xu Zhou ${ }^{3 * *}$ \\ ${ }^{1}$ School of Spatial Informatics and Geomatics Engineering, Anhui University of Science and Technology, \\ Huainan 232001, China \\ ${ }^{2}$ School of Earth and Environment, Anhui University of Science and Technology, Huainan 232001, China \\ ${ }^{3}$ Land Consolidation and Rehabilitation Center, Ministry of Natural Resource, Beijing 100035, China
}

Received: 30 August 2021

Accepted: 20 November 2021

\begin{abstract}
Rapid, accurate, and non-destructive monitoring after land reclamation is the basis of and key to realizing land restoration evaluation, as well as land use direction decision-making and improvement. However, the biggest problem with the filling reclamation method is the poor soil water retention caused by the insufficient thickness of covering soil (TCS), which results in the loss of soil nutrients. In addition, the cost of filling reclamation has also increased due to the excessive TCS. In this study, multi-source remote sensing data acquisition methods were used to assess the impacts of the TCS of the filling reclamation method on soil water retention and crop growth (CG). We found that as the TCS increases, the overall trend of the CG gradually increases, and the overall trend of the soil water content slowly increases. However, considering the huge economic costs and the cost of soil sources, we suggest that the optimal TCS for the filling reclamation method should be controlled within $40-50 \mathrm{~cm}$. The results of this study provide a reference for the use of multi-source remote sensing technology for rapid evaluation of the restoration effects of reclaimed areas and for the rational utilization of coal chemical wastes.
\end{abstract}

Keywords: land reclamation, remote sensing, thickness of covering soil, crop growth, soil water content

\footnotetext{
*e-mail: shwzhangaust@163.com

**e-mail: zhouxu@lcrc.org.cn
} 


\section{Introduction}

With the progress of human civilization, the development of mineral resources has gradually become the basic source of human production and living materials. However, long-term, large-scale, highintensity mining inevitably causes numerous environmental problems [1]. Land reclamation has gradually become an important method of environmental restoration in mining areas, but it is still challenging to efficiently carry out long-term monitoring and research on the effects of reclamation methods without causing damage [2]. In addition, due to the increasing shortage of soil resources, reclamation projects have gradually adopted the filling reclamation method. However, when the reclamation filling method is used, the resultant water-preserving capability of the covering soil is poor, which leads to problems such as a decline in soil fertility and the loss of soil nutrients [3]. Therefore, monitoring of the soil moisture in the reclaimed area is one of the key indicators used to detect the effect of reclamation and restoration measures. The relationships between the thickness of the covering soil (TCS), the soil water content (SWC), and the crop growth (CG) under the reclamation filling method are also increasingly considered to be an important part of the ecosystem in the re-claimed farmland because these relationships determine the growth and succession of crops in the farmland ecosystem [4]. However, soil sampling methods are often used to determine the TCS, the SWC, and the CG, and these methods are timeconsuming, laborious, and destructive to the soil [5]. Although the satellite remote sensing method has the ability to provide spatial information and to quickly obtain the distribution of the target to be measured on a large scale, the scale of the measurement target is relatively large [6]. Due to the inappropriate scope and resolution of the survey, the abovementioned methods cannot meet the accuracy requirements of reclamation effect evaluation.

The unmanned aerial vehicle (UAV) remote sensing technique is a down-scaled remote sensing method relative to satellite remote sensing. With its fast, efficient, and accurate characteristics, the UAV method has gradually become widely used for crop evaluation [7]. In recent years, the near-ground quantitative remote sensing technique based on drones has been shown to have unique advantages [8]. More scholars have carried out a series of studies on crops and have achieved many results. Dehkordi, et al. [9] used high-resolution aerial remote sensing data to study the impact of biochar on farmland crop growth at the canopy level for the first time. Their results showed that the presence of biochar significantly increased the stress on the chicory crops, but the yield of the harvested crops was not affected. $\mathrm{Fu}$, et al. [10] used the UAV remote sensing technique to study wheat test sites, and their results showed that UAV remote sensing has broad application prospects in crop growth index monitoring and yield estimation.
Hassan, et al. [11] used a multi-spectral drone to monitor the normalized difference vegetation index (NDVI) of wheat varieties and breeding lines grown under different irrigation conditions. Their results revealed that the multi-spectral sensor on the drone is a reliable high-throughput NDVI measurement platform and has a good effect in studying the CG. These studies have fully demonstrated that the UAV remote sensing technique has significant advantages in the monitoring of $\mathrm{CG}$ on the mesoscale. How-ever, because UAV remote sensing involves the acquisition of the apparent reflectance, it has limitations in terms of its ability to detect underground properties such as the TCS [12].

In order to explore the impacts of the filling reclamation method on the soil water-preservation capability and $\mathrm{CG}$, it is necessary to determine the distribution of the underground structures in the reclamation area. Therefore, it is essential to conduct non-destructive and accurate acquisition of the TCS. As a geophysical tool, ground penetrating radar (GPR) has a great potential for soil structure investigations. This method can achieve non-destructive detection of underground abnormal structures under a large-area and has the ability to obtain underground information [13]. Liu, et al. [14] used GPR to detect the thickness of the soft soil layer in northeastern China, and their results demonstrated that GPR has a great potential in terms of its ability to identify the soil thickness. Marecos, et al. [15] used GPR to detect the asphalt layer of a road. Their results showed that GPR is of great significance to long-term monitoring of the pavement structure, and it can accurately obtain the thickness of the asphalt layer and the particle layer. Luo, et al. [16] used GPR to analyze the physical soil properties of reclaimed land in a mining area, and their results showed that GPR can accurately obtain the soil layer thickness of reclaimed land and other unnatural sediments. Therefore, in future, GPR can be gradually applied to the detection of the soil thickness and under-ground structures constructed from unnatural sediments.

In addition, GPR is not only a geophysical tool but has also gradually become a near-earth microwave remote sensing technique for the rapid and nondestructive detection of the SWC [17]. After the analysis of the relationship between the soil's dielectric constant and the SWC by Topp, et al. [18] and Knoll, et al. [19], it became possible to use GPR to nondestructively predict the SWC. Cao, et al. [20] used GPR to acquire the SWC and analyzed the spatial variability of the SWC. Their results revealed that GPR has a great potential in investigating the spatial variability of water. Pettinelli, et al. [21] found that the early-time signals of GPR have a strong correlation with the SWC. Algeo, et al. [22] verified that the earlytime amplitude envelope has a good correlation with the SWC in the field environment, and they used it to create a farmland moisture distribution map based on the time series. With the deepening of research, GPR has not only been used for the detection of structures 
but has also gradually become widely used for SWC prediction [23].

In this study, a reclaimed area filled with fly ash, in Huaibei City, eastern China, was taken as the study area. Multi-source remote sensing (GPR and UAV) techniques were used to analyze the impact of the filling reclamation method on the soil moisture accumulation and CG under different TCS values. In addition, the feasibility of heterogeneous layer identification and depth acquisition after the filling reclamation method using GPR was explored, and the potential of using multi-source remote sensing (GPR and UAV) for reclamation effect evaluation was evaluated. Furthermore, the optimal TCS for the filling reclamation method was analyzed from the perspectives of water retention and CG. The results of this study are significant to optimizing reclamation methods and to long-term, rapid, and non-destructive monitoring of the effects of reclamation projects.

\section{Experimental}

\section{Study Area Overview}

The study area is located in Huaibei City, northern Anhui Province, eastern China $\left(33^{\circ} 58^{\prime} \mathrm{N}, 116^{\circ} 51^{\prime} \mathrm{E}\right)$.
The warm semi-humid monsoon climate of this area results in well-marked seasons and more than adequate rainfall. Since Huaibei City is one of China's important coal mining bases, the construction and production of thermal power generation facilities have increased. This has led to the accumulation of a large amount of fly ash, the storage of which occupies a lot of arable land. In the early $21^{\text {st }}$ century, in order to cope with the damage to the land caused by coal mining subsidence and to solve the problem of fly ash accumulation, the local government adopted the fly ash filling reclamation method to restore a large amount of arable land. The study area was one of the farmland areas reclaimed at that time, with an area of about $0.84 \mathrm{~km}^{2}$. Before the reclamation, it was a subsided seeper area, with a maximum collapse depth of $10 \mathrm{~m}$. Due to the large collapsed area, it is inevitable that the filling height is inconsistent and the TCS varied during the construction and accumulation processes. The soil type of the TCS is mainly loam. The TCS is approximately $20-70 \mathrm{~cm}$. The southern and western parts of the study area are adjacent to lakes. The terrain in the study area is flat. The main crops planted are wheat and corn rounds, and the water supply for the crops is rain. The field test was conducted in December, and the winter wheat was in the overwintering period in the study area. The specific situation is shown in Fig. 1.
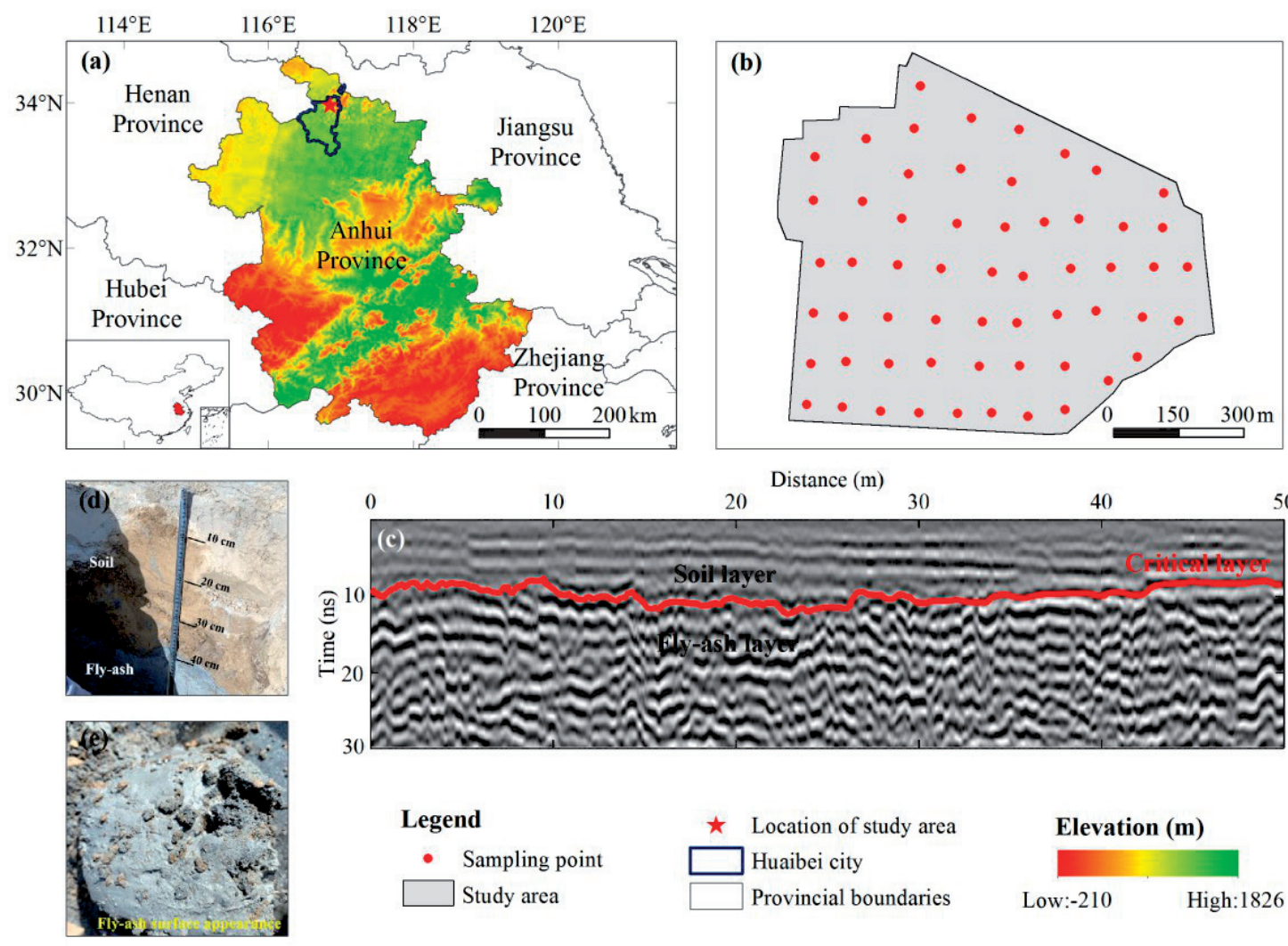

20 Distance $(\mathrm{m})$

$30 \quad 40$

50
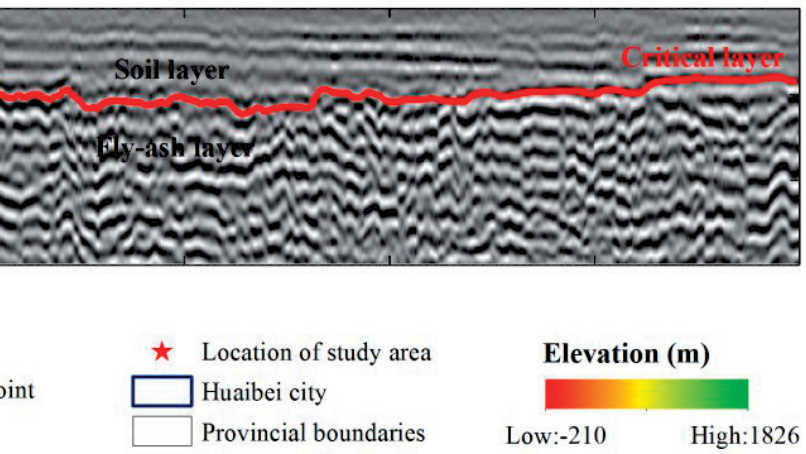

Fig. 1. Overview of the study area: a) location and elevation of the study area in Anhui Province; b) sampling locations ( $\mathrm{n}=58$ ); $\mathrm{c})$ ground penetrating radar pre-experiment results (layered information) for a 50-m line measurement; d) soil profile; and e) fly ash water absorption performance. 
UAV Data Acquisition and Preprocessing

\section{UAV Data Acquisition}

A DJI Phantom 4 (DJ-Innovations, Shenzhen, China) multi-spectral version of the plant protection UAV equipped with an integrated multi-spectral imaging system was used to acquire the multi-spectral images of the reclamation area. The UAV integrates one visible light sensor and five multi-spectral sensors (blue, green, red, red edge, and near infrared). The parameter settings of the UAV should comprehensively consider the research goals. Therefore, in this study, the heading overlap was $70 \%$, and the side overlap was $60 \%$. The UAV was flown at a height of $110 \mathrm{~m}$ and at a speed of $5.1 \mathrm{~m} / \mathrm{s}$, and the sensor lens was oriented vertically downward. The study area is a large winter wheat planting area with relatively few typical features. In order to facilitate the sub-sequent geometric correction processing of the images, 10 aerial survey landmarks were evenly arranged in the survey area as typical reference points. Before the aerial photography was conducted, the aircraft was manually controlled to hover $2.5 \mathrm{~m}$ above the calibration plate to capture images, and the standard reflectance values under the cur-rent conditions were obtained. When the multispectral images were acquired in the study area, the sky was clear, with few clouds and no wind, and the light radiation in-tensity was stable.

\section{UAV Data Preprocessing}

The Pix4D (Pix4D SA, Prilly, Switzerland) Mapper software was used for the post-image stitching after the drone images were acquired. The acquired multispectral images were calibrated and mosaiced before the image processing [24]. The UAV data preprocessing was conducted using the ENVI 5.3 software (Exelis Visual Information Solutions, New York, USA). First, 30 reference points (including 10 aerial survey landmark points) were uniformly selected throughout the area to geometrically correct the multi-spectral images. According to the location of the ground sample points in the image, the region of interest (ROI) of the sample points was constructed. The average reflectance spectrum value in the ROI range was taken as the winter wheat reflectance spectrum at this point in order to obtain the reflectance spectrum data for each sample point.

\section{Ground Penetrating Radar Data Acquisition and Preprocessing}

\section{GPR Data Acquisition}

A PRO-EX ground penetrating radar instrument (Mala Geoscience, Malå, Sweden) was used to acquire the GPR data for the reclamation area. Considering that the reclamation area is large and most of the plots have been planted with winter wheat, the GPR test included a 50-m long survey line for the pre-experimental analysis and 58 radar survey points for detection. Considering the TCS, the dielectric properties of the soil, and the energy loss during detection, the antenna center frequency was set to $500 \mathrm{MHz}$; the time window was set to $40 \mathrm{~ns}$; the number of sampling points was 1024; and the fixed offset measurement method was used. Twenty radar measurements were taken at each sampling location. Soil samples were collected at the calibration position after the radar detection was completed. In order to reduce the interference of the surface heterogeneity, the surface impurities on the radar survey line were simply cleaned up before the detection.

\section{GPR Data Preprocessing}

Electromagnetic waves cause various interferences such as energy attenuation and dispersion during propagation in a soil medium; so, it is necessary to preprocess the radar data to improve the accuracy of the data [25]. Due to the different uses of GPR data (SWC and TCS), there are also certain differences in the preprocessing methods used for different purposes. It should be noted that due to multiple reasons, such as the undulation of the ground, there will be inconsistencies in time zero. We used the short-termaverage (STA) over long-term-average (LTA) method to automatically extract the time zero position of the electromagnetic wave signal of the GPR, in order to accurately obtain the travel time of the electromagnetic wave. This method was first proposed by Stevenson [26] to identify the arrival of microseismic waves. The STA/LTA was obtained using the following equations:

$$
\begin{array}{r}
\operatorname{LTA}(i)=\frac{1}{N_{L}} \sum_{j=i}^{i+N_{L}} C F(j), \\
S T A(i)=\frac{1}{N_{S}} \sum_{j=i+N_{L}}^{i+N_{L}+N_{S}} C F(j), \\
\operatorname{STA} / \operatorname{LTA}(i)=\frac{\operatorname{STA}(i)}{\operatorname{LTA}(i)} \geq \lambda,
\end{array}
$$

where $N_{S}$ and $N_{L}$ are the numbers of samples in the STA and LTA time windows, respectively. The time window used in this study was $N_{S}=40$ and $N_{L}=200$. $\lambda$ is the trigger threshold, and $C F$ is the characteristic function. The $C F$ function used in this study was an improved feature function of Liu, et al. [27]. It introduces a weighting factor $K$, which has the advantages of noise resistance and a strong stability. The $C F$ function is expressed as follows:

$$
K=\sum_{i=1}^{l e n}|X(i)| / \sum_{i=1}^{l e n}\left|X^{\prime}(i)\right|,
$$




$$
C F=X(i+1)^{2}+K(X(i+1)-X(i))^{2},
$$

where $K$ is based on the signal sampling frequency and the nature of the noise in order to carry out the weight distribution. The $C F$ includes the signal amplitude and frequency parameter characteristics, which greatly improve its noise resistance and stability. len is the length of the input signal; and $X(i)$ is the amplitude of the signal at $i . X^{\prime}(i)$ is the derivative of $X(i)$. As shown in Fig. 2c), its stability and accuracy are extremely high.

The processing tools used were Reflex-Win 7.2 (Sandmeier Scientific software, Karlsruhe, Germany) and MATLAB. The preprocessing steps included DC drift removal, a time zero search, direct wave removal, gain, background removal, and signal filtering processing. The purpose of the gain is to compensate for the energy lost through the attenuation, scattering, and dissipation of the electromagnetic waves during propagation through the underground medium in order to enhance the visibility of the fly ash-soil critical layer [28]. Since the GPR data contain background noise, which is mainly caused by the horizontal frequency band created by the antenna-ground interaction, multiple underground reflections, and high-frequency spike events, we conducted background removal processing [29]. Following this step, band-pass filtering was used to eliminate the high-frequency and lowfrequency noise. The band-pass was 1.5 times the center frequency [30] of the GPR, and the low (highpass filter) and high (low-pass filter) boundaries were evenly distributed near the center frequency (the highpass filter was $100 \mathrm{MHz}$ and the low-pass filter was $900 \mathrm{MHz}$ ). The fly ash-soil critical layer could be identified in the A-Scan (one-dimensional scan) after the data processing (Figs 2e and 2f).

In order to obtain accurate information about the TCS, we used the travel time of the electromagnetic wave in the soil to determine its specific depth. The formula is as follows:
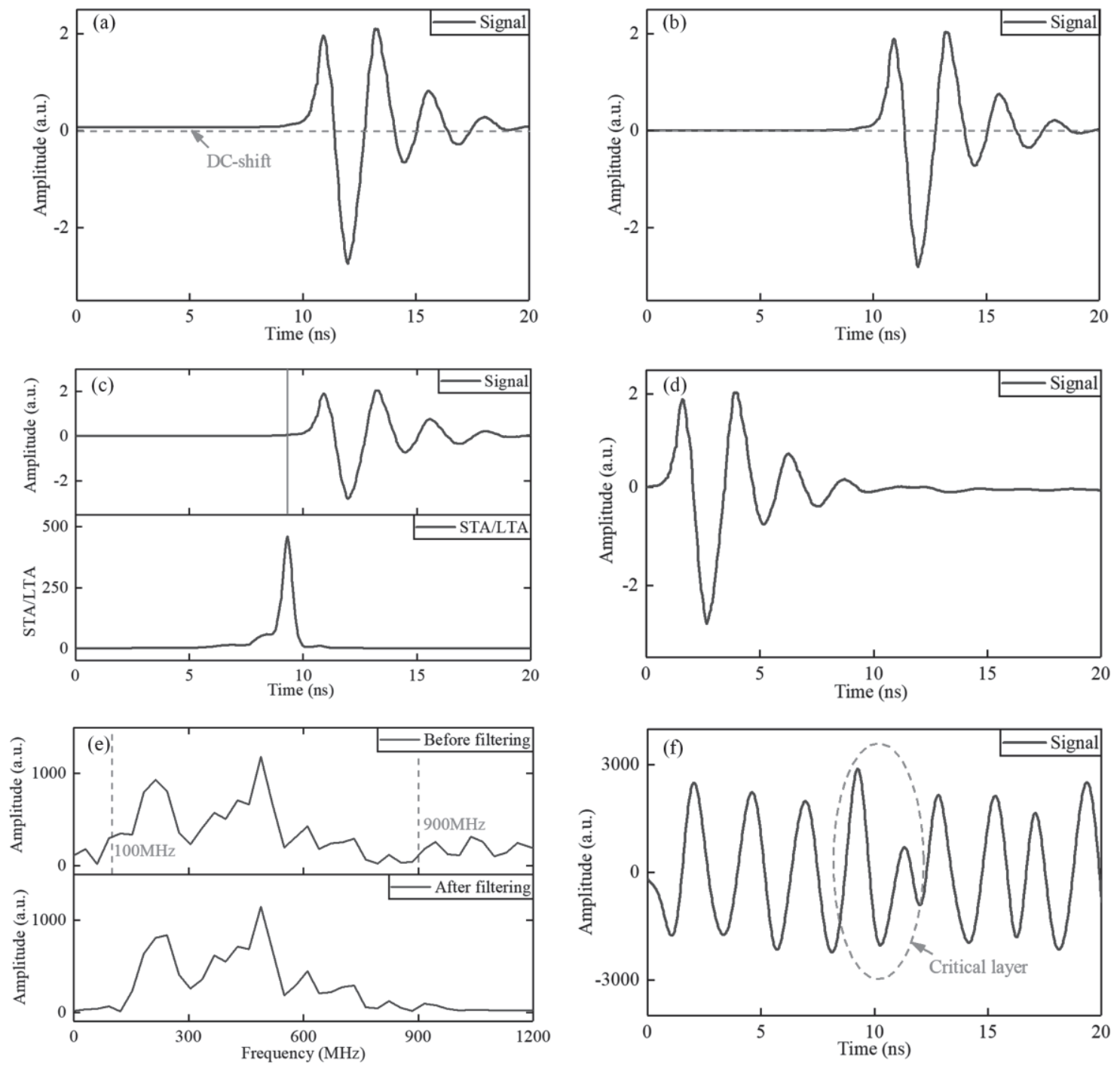

Fig. 2. GPR data preprocessing: a) raw GPR data; b) GPR data after removal of the DC shift; c) and d) STA/LTA method to find the time zero; e) bandpass filter (high-pass filter: $100 \mathrm{MHz}$; low-pass filter: 900MHz); and f) final data used to identify the critical layer. 


$$
v=\frac{c}{\sqrt{\varepsilon}},
$$

where $\mathrm{v}$ is the wave speed of the electromagnetic waves propagating through the soil, which is the dielectric constant of the soil, and $\mathrm{c}$ is the speed of light. Then, using Topp's formula [18],

$$
\varepsilon=3.03+9.3 \theta_{v}+146.0 \theta_{v}^{2}-76.0 \theta_{v}^{3},
$$

where $\theta_{v}=\rho \times \theta_{m} ; \theta_{v}$ is the soil volumetric water content; $\rho$ is the soil's dry bulk density (DBD); and $\theta_{m}$ is the water content of the soil mass. We can obtain the travel velocity $(v)$ of the electromagnetic waves in the soil using Equation (6). Therefore, we can obtain the TCS as follows:

$$
\begin{aligned}
& S=v t_{\text {travel }}, \\
& h=S / 2,
\end{aligned}
$$

where $t_{\text {travel }}$ is the travel time of the electromagnetic wave in the soil; $S$ is the two-way distance that the electromagnetic wave reflects during travel; and $h$ is the TCS.

\section{Soil and Crop Data Collection}

\section{Soil Data Acquisition}

The collection of the soil's DBD, SWC, and compactness data was carried out at the sampling points in the study area. The cutting ring method was used to collect the soil data. The plum blossom sampling method was used to collect soil samples at $15 \mathrm{~cm}$ at each sample point. The soil samples were transported to the laboratory and placed in a dryer at $105^{\circ} \mathrm{C}$ for $24 \mathrm{~h}$. After drying, the dry weight of each soil sample was obtained. The DBD and SWC were calculated as follows:

$$
\begin{aligned}
& \rho=\frac{M-m}{V}, \\
& \theta=\frac{M-m}{m},
\end{aligned}
$$

where $\rho$ is the DBD of the soil; $M$ is the weight of the soil before drying; $m$ is the weight of the soil after drying; $V$ is the volume of the cutting ring; and $\theta$ is the SWC.

An SC-900 (Spectrum Technologies, Aurora, USA) soil compactness tester was used to acquire the soil compactness data. The measurement unit was $\mathrm{kPa}$; the resolution was $2.5 \mathrm{~cm}$; the measurement accuracy was $\pm 35 \mathrm{kPa}$; the maximum range was $45 \mathrm{~cm}$; and the measurement pressure range was 0-7000 $\mathrm{kPa}$. The compactness was tested three times at each sample point, and the average value was taken as the final compactness.

\section{Crop Data Acquisition}

In order to quantify the growth of the winter wheat in the study area, the single CG index did not consider the characteristics of the winter wheat's morphological, physiological, and biochemical characteristics [9]. In this study, we used a combination of morphological indicators (crop height), physiological and biochemical indicators (leaf pigments), stress indicators (water), and yield indicators (biomass) to quantify the comprehensive growth of the winter wheat. The chlorophyll content of the crops was measured using a SPAD-502 (Konica Minolta, Tokyo, Japan) chlorophyll meter for 58 sampling points in the study area. Each sampling point was selected in the range of $1 \mathrm{~m} \times 1 \mathrm{~m}$; three high, medium, and low crops were selected; and two leaves from each crop were measured to determine the chlorophyll content of the tip, middle, and base of the leaf. The average chlorophyll content was taken as the final chlorophyll content of the sample. The crop height was defined as the distance from the highest leaf tip to the base of the stem of the winter wheat that grows naturally, and it was measured using a ruler. After the leaf samples were separated, they were placed in an oven at $105^{\circ} \mathrm{C}$ for $30 \mathrm{~min}$, and all of the crop samples were dried for $48 \mathrm{~h}$ at $80^{\circ} \mathrm{C}$. Subsequently, the crop biomass index and water content index were calculated as follows:

$$
\theta_{\text {crop }}=\frac{M_{1}+M_{2}-m_{1}-m_{2}}{M_{1}+M_{2}} \times 100 \%,
$$

where $\theta_{\text {crop }}$ is the crop's water content; $M_{1}$ is the fresh weight of the crop leaf; $M_{2}$ is the fresh weight of the stem; $m_{1}$ is the weight of the crop leaf after drying; and $m_{2}$ is the weight of the stem after drying.

\section{UAV Vegetation Index Selection and Crop Growth}

\section{Vegetation Index Selection}

Crops exhibit different spectral reflectances in different wavebands because of the differences in their intrinsic biochemical parameters [31]. The vegetation index refers to the linear or non-linear combination of the spectral reflectance in the characteristic band, and it can be used to diagnose the growth state of vegetation and to invert various vegetation parameters. However, the response relationships between the vegetation index constructed in different wavebands and the target object are different. The condition of the crop is closely related to the spectral reflectance information in the red band, red edge band, and near-infrared band [32]; so, there are 16 vegetation indices composed of the red band, red edge band, and near-infrared band. 


\section{Construction Method of the Comprehensive Growth Monitoring Index (CGMI)}

Due to the different weights of the winter wheat chlorophyll, biomass, crop height, and water content in the CGMI, we adopted the coefficient of variation method to construct the CGMI. The coefficient of variation method is used to determine the weighted value of the evaluation index according to the degree of variation of each evaluation index value [43]. The variation coefficient is calculated to determine the weighting method as follows:

$$
\begin{gathered}
V_{\mathrm{i}}=\frac{\sigma_{i}}{\bar{x}_{i}}(i=1,2, K, n), \\
W_{\mathrm{i}}=\frac{V_{i}}{\sum_{i=1}^{n} V_{i}},
\end{gathered}
$$

where $V_{i}$ is the coefficient of variation; $\sigma_{\mathrm{i}}$ is the standard deviation; $\bar{x}_{i}$ is the average; and $W_{i}$ is the weight.

\section{Early-Time Signal Amplitude Envelope of Ground Penetrating Radar}

Ground penetrating radar data contain a large amount of information about the underground media [44]. In this study, the average envelope amplitude (AEA) was used as the characteristic parameter of the GPR in order to analyze the response relationship between it and the SWC. This method, which is based on early-time amplitude analysis, was first proposed by Pettinelli, et al [21]. The early-time signal refers to the radar wave in the first positive half cycle. The Hilbert transform can be used to obtain the value of the envelope's amplitude, and the value of the envelope's amplitude in the time window (first positive half cycle) is averaged to obtain the AEA (Fig. 3).

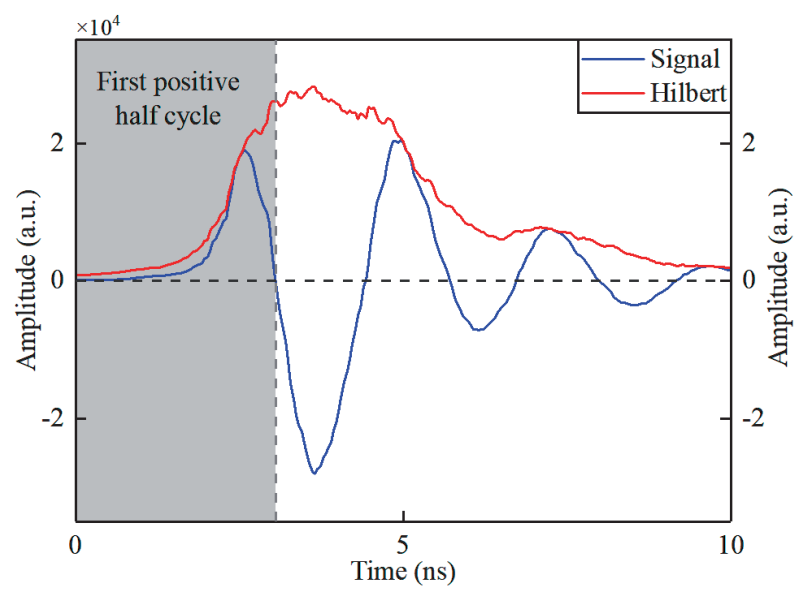

Fig. 3. Hilbert transform of GPR data.

\begin{tabular}{|c|c|c|}
\hline $\begin{array}{l}\text { Vegetation } \\
\text { index }\end{array}$ & Formula & Reference \\
\hline $\mathrm{CI}_{\text {green }}$ & $\mathrm{CI}_{\text {green }}=\mathrm{NIR} / \mathrm{GREEN}-1$ & {$[33]$} \\
\hline DVI & $\mathrm{DVI}=\mathrm{NIR}-\mathrm{RED}$ & {$[34]$} \\
\hline EVI2 & $\begin{array}{l}\mathrm{EVI} 2=(\mathrm{NIR}-\mathrm{RED}) / \\
(1+\mathrm{NIR}+2.4 \mathrm{RED})\end{array}$ & {$[35]$} \\
\hline GNDVI & $\begin{array}{c}\text { GNDVI }=(\text { NIR }- \text { GREEN }) / \\
(\text { NIR+GREEN })\end{array}$ & {$[36]$} \\
\hline MSR & $\begin{aligned} \mathrm{MSR}= & (\mathrm{NIR} / \mathrm{RED}-1) /(\mathrm{NIR} / \\
& \mathrm{RED}+1)^{\wedge} 0.5\end{aligned}$ & {$[37]$} \\
\hline MTCI & MTCI $=($ NIR-REG $) /($ REG-RED $)$ & {$[38]$} \\
\hline MVI & $\begin{array}{l}\mathrm{MVI}=[(\mathrm{NIR}-\mathrm{RED}) / \\
(\mathrm{NIR}+\mathrm{RED})+0.5]^{\wedge} 0.5\end{array}$ & {$[36]$} \\
\hline NDGI & $\begin{array}{l}\text { NDGI }=(\text { GREEN-RED }) / \\
(\text { GREEN+RED })\end{array}$ & {$[34]$} \\
\hline NDVI & $\mathrm{NDVI}=(\mathrm{NIR}-\mathrm{RED}) /(\mathrm{NIR}+\mathrm{RED})$ & [39] \\
\hline NLI & $\mathrm{NLI}=\left(\mathrm{NIR}^{\wedge} 2-\mathrm{RED}\right) /\left(\mathrm{NIR}^{\wedge} 2+\mathrm{RED}\right)$ & {$[40]$} \\
\hline OSAVI & $\begin{array}{l}\text { OSAVI }=(\mathrm{NIR}-\mathrm{RED}) / \\
(\mathrm{NIR}+\mathrm{RED}+0.16)\end{array}$ & [41] \\
\hline RDVI & $\begin{array}{l}\mathrm{RDVI}=(\mathrm{NIR}-\mathrm{RED}) / \\
\quad(\mathrm{NIR}+\mathrm{RED})^{\wedge} 0.5\end{array}$ & {$[42]$} \\
\hline SAVI & $\begin{array}{c}\text { SAVI }=(1+\mathrm{L})(\mathrm{NIR}-\mathrm{RED}) / \\
(\mathrm{NIR}+\mathrm{RED}+\mathrm{L})(\mathrm{L}=0.5)\end{array}$ & {$[36]$} \\
\hline RVI & $\mathrm{RVI}=\mathrm{NIR} / \mathrm{RED}$ & {$[34]$} \\
\hline RVI1 & RVI1 $=$ NIR/GREEN & {$[36]$} \\
\hline TVI & $\begin{array}{c}\text { TVI }=0.5 \times[120(\mathrm{NIR}- \\
\text { GREEN })]-200(\text { RED }- \text { GREEN })\end{array}$ & {$[40]$} \\
\hline
\end{tabular}

Table 1. Multi-spectral vegetation indexes and their formulas.

Note: GREEN, RED, REG, and NIR denote the reflectance values in the green, red, red edge, and near infrared bands, respectively.

The advantage of this method is that when the air and ground waves are mixed, the wave velocity inversion method fails; so, this method can be used to mine the characteristic variables from the electromagnetic wave attribute information (instantaneous amplitude) and to characterize the SWC information. Later, Di Matteo, et al. [45] defined the theoretical basis of the AEA based on continuous research.

Therefore, the Hilbert transform of the time-domain radar data was obtained as follows:

$$
\hat{x}(t)=\frac{1}{\pi} \int_{-\infty}^{+\infty} \frac{x(s)}{t-s} d s,
$$

where $\hat{x}(t)$ is the Hilbert transformation function of $x(s)$, and the integral is the value integral of the Cauchy principle. The complex imaginary part of the radar signal $x_{i}(t)$ is generated after the Hilbert transformation, and the GPR signal $x_{t}(t)$ is regarded as the real part of the signal. Its form is as follows: 
Table 2. Statistical analysis of the crop data.

\begin{tabular}{|c|c|c|c|c|c|}
\hline Crop growth index & Minimum & Maximum & Mean & STD & CV $(\%)$ \\
\hline Chlorophyll content & 29.68 & 53.12 & 36.67 & 5.15 & 14.05 \\
\hline Crop height $(\mathrm{cm})$ & 6.50 & 18.70 & 12.09 & 2.682898 & 22.19 \\
\hline Biomass $(\mathrm{g})$ & 0.26 & 4.94 & 2.19 & 0.960676 & 43.90 \\
\hline Crop water content $(\%)$ & 36.96 & 72.28 & 63.93 & 5.66 & 8.85 \\
\hline
\end{tabular}

$$
\begin{aligned}
\hat{x}(t) & =x_{r}(t)+j x_{i}(t), \\
\bar{A}_{i}(t) & =\sqrt{x_{r}^{2}(t)+x_{i}^{2}(t)},
\end{aligned}
$$

where $j=\sqrt{-1}$, and $\bar{A}_{i}(t)$ is the instantaneous amplitude. Therefore, the AEA can be defined as the average value of the instantaneous amplitude (amplitude envelope) within a specific time window.

\section{Results and Discussion}

\section{CGMI Inversion Based on UAV}

\section{Constructing the CGMI}

The variations in the TCS result in the soil conditions being more complex than those of normal soil. To achieve a more accurate characterization of the CG, 58 crop samples (chlorophyll, crop height, biomass, and crop water content) were acquired from the study area and analyzed. Table 2 presents the results of the statistical analysis of the measured data. We found that the average values of the chlorophyll content, crop height, and crop water content were $36.67,12.09 \mathrm{~cm}$, and $64 \%$, respectively; and their coefficients of variation (CVs) were $14.05 \%, 22 \%$, and $8.85 \%$, respectively. For the biomass, the average value was $2.19 \mathrm{~g}$, and its $\mathrm{CV}$ was $43.90 \%$, which is the largest of all the indicators.
In general, the TCS variations in the study area have increased the spatial variability of the $C G$ to a certain extent. Due to the large variability of the various biological indicators, the $\mathrm{CV}$ method was used to assign weights to the different biological indicators. The CGMI of the winter wheat was constructed as follows:

$\mathrm{CGMI}=0.166 X_{1}+0.246 X_{2}+0.489 X_{3}+0.099 X_{4},(18)$

where $X_{1}$ is the chlorophyll content; $X_{2}$ is the crop height; $X_{3}$ is the biomass; and $X_{4}$ is the crop water content.

\section{Correlation Analysis and Variable Selection of Vegetation Index and CGMI}

In order to screen out the best selected variables for the model, Pearson correlation analysis was performed between the CGMI and the 16 vegetative indexes (Table 3). It was found that the $\mathrm{CI}_{\text {green }}$, GNDVI, MTCI, and RVI1 indexes have very low correlations with the CGMI (Table 3), but the remaining vegetation indexes are all extremely significantly correlated with the CGMI. The TVI and NDGI have the highest correlation coefficients (0.580) with the CGMI, indicating significant correlations. We selected the 12 vegetation indexes that are extremely significantly correlated with the CGMI based on the above analysis.

Multi-collinearity of the vegetation indexes can cause problems such as instability or over-fitting of the model. Therefore, we selected the variance inflation factor (VIF) to analyze the multi-collinearity between the input variables (vegetation indexes) of the model

Table 3. Correlations between the vegetation indexes and the CGMI.

\begin{tabular}{|c|c|c|c|}
\hline Vegetation index & Correlation coefficient & Vegetation index & Correlation coefficient \\
\hline CIgreen & 0.167 & NDVI & $0.437^{* *}$ \\
\hline DVI & $0.454^{* *}$ & NLI & $0.346^{* *}$ \\
\hline EVI2 & $0.445^{* *}$ & OSAVI & $0.440^{* *}$ \\
\hline GNDVI & 0.178 & RDVI & $0.446^{* *}$ \\
\hline MSR & $0.433^{* *}$ & SAVI & $0.443^{* *}$ \\
\hline MTCI & 0.046 & RVI & $0.422^{* *}$ \\
\hline MVI & $0.428^{* *}$ & RVI1 & 0.167 \\
\hline NDGI & $0.580^{* *}$ & TVI & $0.580^{* *}$ \\
\hline
\end{tabular}

Note: $*$ denotes significant at the 0.05 level, $* *$ denotes significant at the 0.01 level. 
[46]. The VIF values of the 12 vegetation indexes were calculated, and $\mathrm{VIF}<10$ was used as the screening condition. Finally, six vegetation indexes (DVI, MSR, MVI, NDGI, NLI, and TVI) were used as the final input variables of the model.

\section{CGMI Inversion}

Due to the error of the instrument itself and many other accidentally introduced factors, in the actual sampling, abnormal data are incorporated into the acquired data. We used residual analysis to eliminate the abnormal data before the model was constructed [47]. Three abnormal points were eliminated, and 55 samples were used in the model construction process. The samples were stratified: 18 samples were used as the validation set and 37 samples were used as the modeling set. The extreme learning machine (ELM) algorithm was used for the model construction and prediction based on the six selected variables of the model (vegetation indexes). The growth status of the winter wheat in the study area was obtained through the model. Fig. 2a) shows the effect map of the normalized CGMI in the study area. As can be seen, the spatial variability of the growth of the winter wheat is relatively large in the study area. The growth of the winter wheat in the central and southern parts of the study area was average, and the growth in the eastern area was better. In general, the growth of the winter wheat in the study area was moderate. Fig. 4b) shows that the $R^{2}$ of the model constructed using the ELM is 0.70 and the RMSE is 0.07 . Fig. 4c) shows that the standard residuals are all between -2 and 2 and are normally distributed. In summary, the model has a good effect and can accurately invert the CG in the study area.

\section{Recognition of TCS and SWC Inversion \\ Analysis of the Data Detection Results of the Pre-Experiment in the Research Area}

A pre-experiment (feasibility verification) was performed by setting up an 50-m long survey line in the study area. The GPR was used for the detection, and the SWC of 25 samples (2 m apart) was collected along the survey line. A total of five waveforms before and after each sampling point were averaged in order to eliminate any small-scale changes (outliers) and the error of the instrument's detection distance. The AEA value corresponding to each sampling point was obtained, and regression analysis of the SWC and AEA was performed (Fig. 5). We found that the AEA exhibited a negative correlation with the SWC, with a Pearson's correlation coefficient of -0.79 , which is significant $(p<0.01)$, and an $R^{2}$ value of 0.62 . In addition, the delamination phenomenon was obvious from the B-Scan (Fig. 1c), and we found that the TCS is not at the same height. The results revealed that GPR can be used to detect the critical soil-fly ash layer and to predict the SWC of the plough layer.

\section{Recognition of TCS}

In order to explore the possibility of the accurate identification of the TCS using GPR, we used the B-Scan (two-dimensional scan) of the GPR data to determine the suspected interval and to accurately pick the first maximum reflection peak in the A-Scan as the receiving point. In this way, the travel time of the electromagnetic wave in the covering soil can
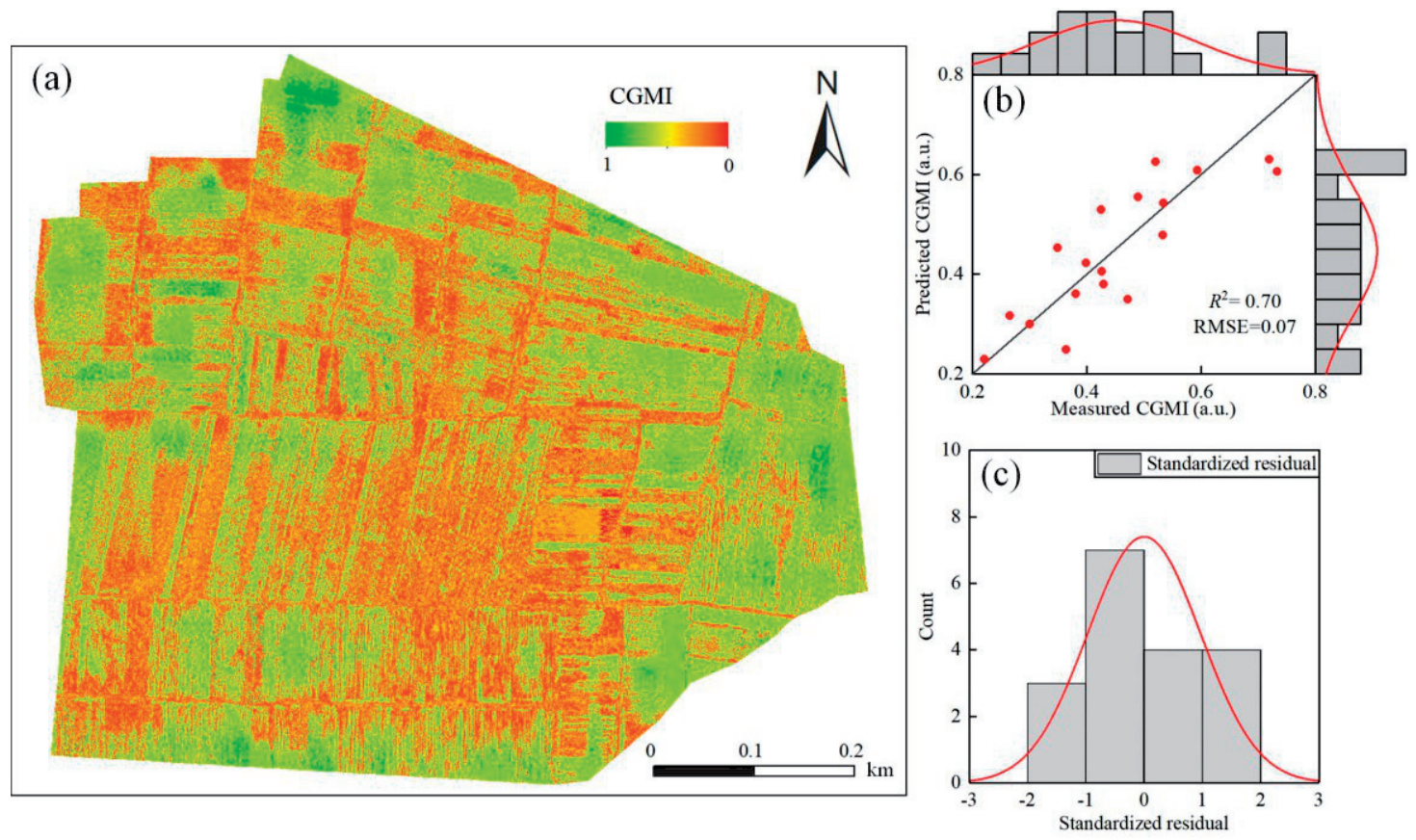

Fig. 4. The effect of the crop growth in the study area based on the UAV inversion. 


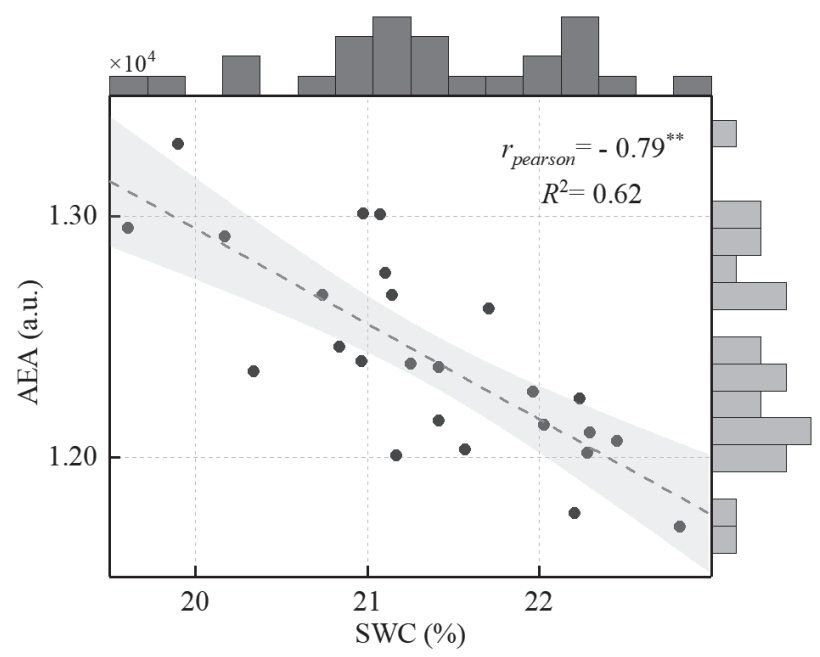

Fig. 5. Analysis of the relationship between the AEA and moisture content in the pre-experiment.

be accurately obtained, and an accurate TCS was obtained. We adopted the compactness as supporting evidence of the ability of this geophysical method to ensure the accuracy of the TCS of each sample point in the study area. As can be seen from Figs 6a) and $6 \mathrm{~b})$, the B-Scan and A-Scan can accurately identify the position of the reflection peak; and the travel time was 7.7 ns. According to Eq. (6), the speed was $0.092 \mathrm{~m} / \mathrm{ns}$, and finally, the TCS was $35.4 \mathrm{~cm}$. In addition, as can be seen from Fig. 6c), the soil compactness changes abruptly at $35 \mathrm{~cm}$ and then gradually becomes stable; so, we conclude this change to be roughly equivalent to the critical layer. Finally, the TCS information for all of the samples was obtained using this method.

\section{Acquisition of SWC}

Since the study area was a filling reclamation area, it was necessary to consider the spatial heterogeneity directly or indirectly caused by the variations in the TCS. In this study, the main method of dealing with the spatial heterogeneity, i.e., the geographically weighted regression (GWR) model, was used to construct the moisture inversion model. It is a non-parametric local spatial regression analysis method for modeling independent variables and dependent variables with spatial variations. The biggest advantage of the GWR is that it considers the spatial heterogeneity. In addition, the SWC is greatly affected by the physical properties of the soil. We selected representative physical properties of the soil (soil dry bulk density and compactness) and the GPR characteristic index (AEA) to analyze their correlation with the SWC (Table 4). We found that the DBD, AEA, and compactness were all significantly correlated with the SWC.

Therefore, the DBD, compactness, AEA, and TCS were selected as the input variables of the model, and the SWC was selected as the dependent variable of the model. Fifty-eight sample points were input to the GWR model, and the leave-one-out cross-validation method was used to evaluate the model's accuracy. Fig. 7a) shows the spatial distribution map of the SWC obtained using the ordinary Kriging interpolation of the model prediction values. It was found that the distribution of the SWC exhibits a certain trend, that is, it is low in the middle and high in the north and south-west. Figs 7b) and 7c) show that the R2 and RMSE values of the SWC inversion model established using the GWR are 0.81 and $0.81 \%$, respectively. Moreover, the standard residuals are almost all distributed between -2 and 2 , which indicates that the model's prediction effect
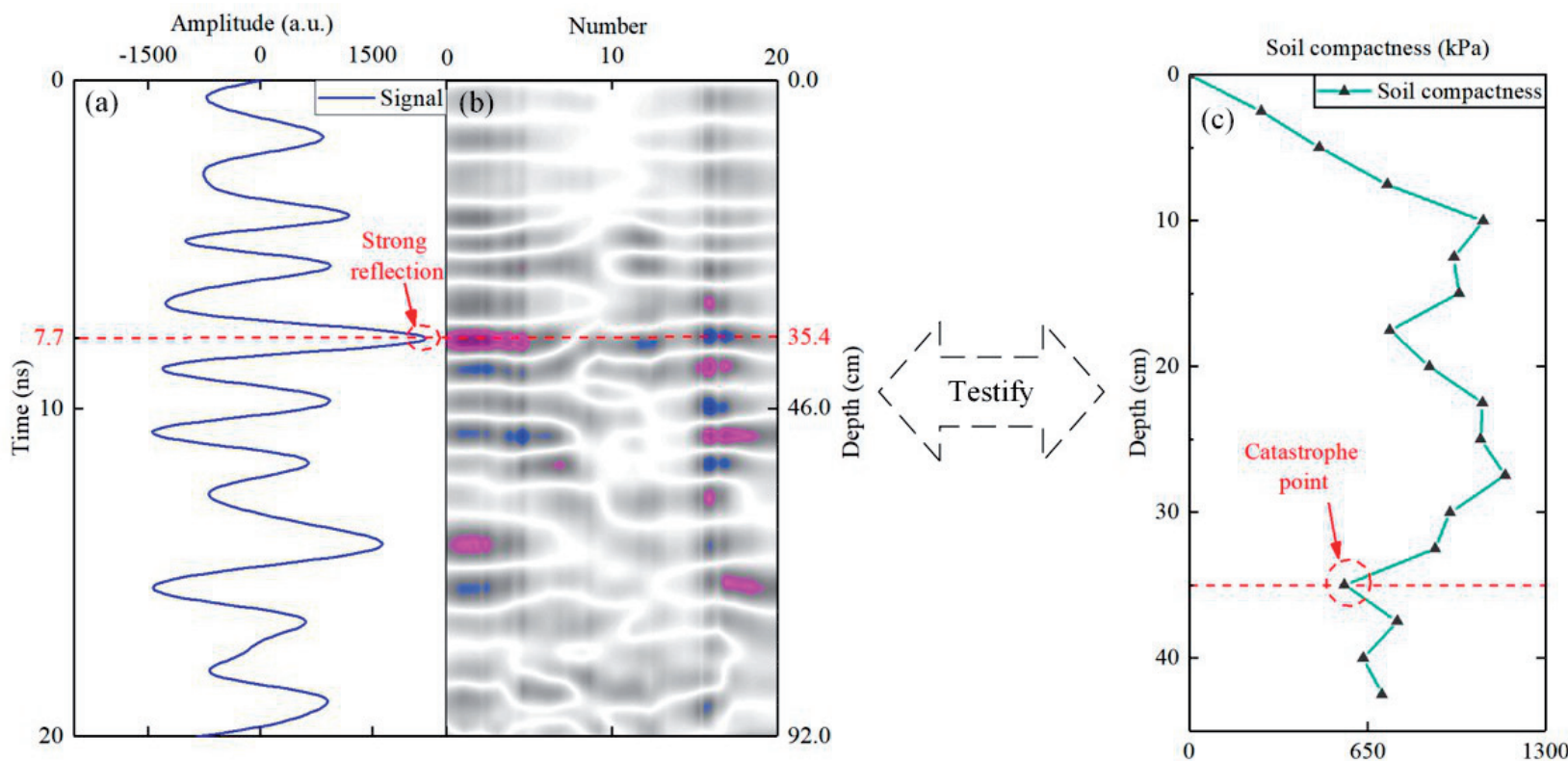

Fig. 6. Recognition of the TCS based on GPR data. 
Table 4. Correlation analysis between the GWR variables and the SWC.

\begin{tabular}{|c|c|c|c|}
\hline Index & Compactness & DBD & AEA \\
\hline Correlation coefficient & $-0.65^{* *}$ & $-0.59^{* *}$ & $-0.81^{* *}$ \\
\hline
\end{tabular}

Note: * denotes significant at the 0.05 level, $* *$ denotes significant at the 0.01 level.
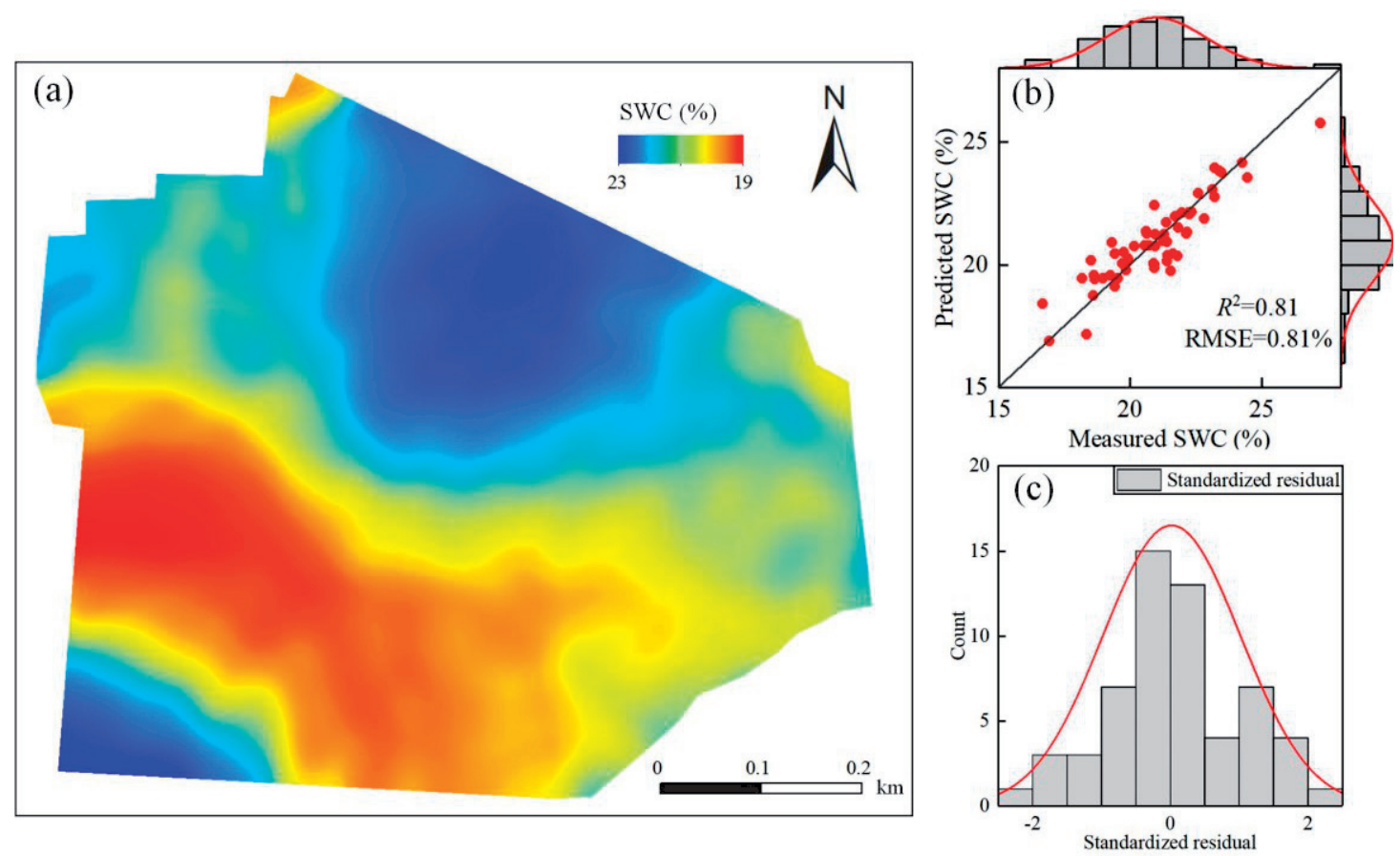

Fig. 7. The effect of the water retrieval based on ground penetrating radar data.

is good. In summary, GPR has a great potential for the detection of the SWC.

\section{Analysis of the Influences of the Variation in the TCS on the SWC and CG}

To analyze the impacts of the fly ash filling reclamation method on the SWC and CG with a variable TCS, in this study, the TCS data obtained via GPR were divided into five intervals: $<30,30-40$, $40-50, \quad 50-60$, and $>60 \mathrm{~cm}$. We analyzed the measurement data (SWC and CGMI) in the different TCS ranges to explore the impact of the TCS on the SWC and CGMI. The average values of the CGMI and GWC in each TCS range were taken as the final values representing the TCS range. Fig. 8 shows that as the TCS increased, the overall trend of the CGMI gradually increased. The results show that the thicker the TCS, the better the CG. In addition, we found that the CGMI was the lowest when the TCS was less than $30 \mathrm{~cm}$, and the CGMI began to increase slowly when the TCS reached $40-50 \mathrm{~cm}$. As the TCS increased, the overall trend of the SWC increased. However, the SWC increased slowly when the TCS reached more than 30 $\mathrm{cm}$. This may be because the depth of this sampling was located in the plough layer $(20 \mathrm{~cm}$ in depth). As the
TCS increased, the influence of the fly ash layer on the SWC of the plough layer gradually decreased. However, the SWC was the lowest when the TCS was less than $30 \mathrm{~cm}$. The results show that the TCS was too low, which affected the supply and migration of the water in the plough layer. We found that the TCS affects the reclamation effect. However, it should be noted that given the current very short supply of soil resources,

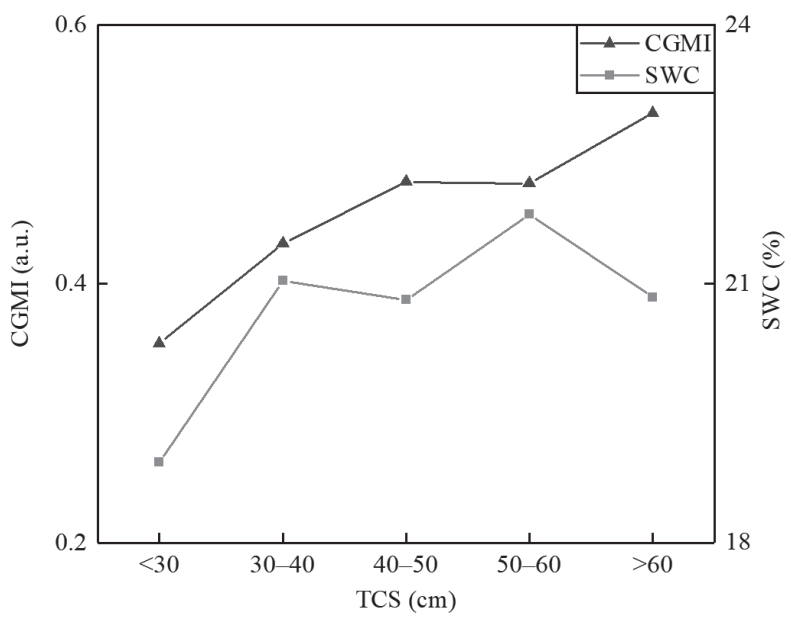

Fig. 8. CGMI and GWC changes with increasing TCS. 
an extra $10 \mathrm{~cm}$ of TCS means a huge increase in the cost of the reclamation. Therefore, the CGMI will gradually decrease as the TCS increases; and the SWC is at a normal level, when the TCS reaches $40-50 \mathrm{~cm}$. In summary, considering the economic costs and available resources, the TCS of the filling reclamation method should be controlled within the range of $40-50 \mathrm{~cm}$.

\section{Analysis of the Relationship between the SWC and CGMI for Reclaimed Soil Filled with Fly Ash}

The soil water content is an important factor in maintaining the energy balance on the Earth's surface. The amount of SWC in the soil determines its material and nutrient transport capacity [48]. We found that the variation in the SWC for a given TCS seems to be a key factor affecting the $\mathrm{CG}$ when studying the influence of the TCS on the CG. Therefore, we analyzed the influence of the SWC on the CG. Since the changes in the TCS will affect the CG, the sample points were divided into three categories $(30-40 \mathrm{~cm}, 40-50 \mathrm{~cm}$, and $>50 \mathrm{~cm}$ ) according to the TCS. The classified samples were divided into six ranges $(<19 \%, 19-20,20-21$, $21-22,22-23$, and $>23 \%$ ) according to the GWC range. The average of the CGMI in each range was used as the SWC of the range. The results are shown in Fig. 9a). It was found that the CGMI is generally lower in the three TCS ranges when the SWC is less than $19 \%$. As the GWC increases, the CGMI of the different TCS ranges gradually increases. The CGMI generally decreases and gradually stabilizes when the GWC is greater than $21 \%$. In addition, we found that the SWC changes more slowly within the TCS range of $30-40 \mathrm{~cm}$. The response degree of the CGMI under different SWC ranges increases as the TCS increases. Thus, the fly ash has a strong water absorption ability and low nutrient content [49]. The lower the TCS, the closer the plough layer will be to the fly ash layer. Therefore, under different SWC ranges, the CGMI changes more slowly at low TCS values. However, the nutrient migration law of the plough layer gradually approaches normal as the TCS increases [50].

Next, we expanded the range of the TCS $(30-50 \mathrm{~cm}$, 40-60 cm, and all samples), and the results are shown in Fig. 9b). We found that the trend of the response relationship between the CGMI and CWC in the three TCS ranges is highly consistent. The CGMI in all of the TCS ranges reached the maximum when the GWC was $19 \%-21 \%$. In summary, the results show that the best SWC for winter wheat in the reclaimed area is $19 \%-21 \%$. When the SWC is too low, it will supply insufficient nutrients to the winter wheat; and when the SWC is too high, respiration of the wheat will be prevented and root rot will occur [51].

\section{Potential and Limitations of Multi-Source Remote Sensing Reclamation Effect Evaluation}

In the past, research on SWC, TCS, CG, and other information was mostly conducted by using manual measurement methods to obtain the sample information. These methods not only destroy the original soil environment and/or CG but also fail to accurately obtain sample information in a large-scale research area. In this study, the UAV multi-spectral remote sensing technique was used to obtain nondestructive information about the CG throughout the entire study area. In addition, GPR was used to obtain non-destructive information about the TCS and the SWC of the plough layer. The relationships between the TCS, SWC, and CGMI in the reclaimed area filled with fly ash were explored using a combination of UAV and GPR methods. The advantage of using the coupled multi-source remote sensing method is that multi-source remote sensing can be used to accomplish large-area detection in a short time, which overcomes the expensive and time-consuming disadvantages
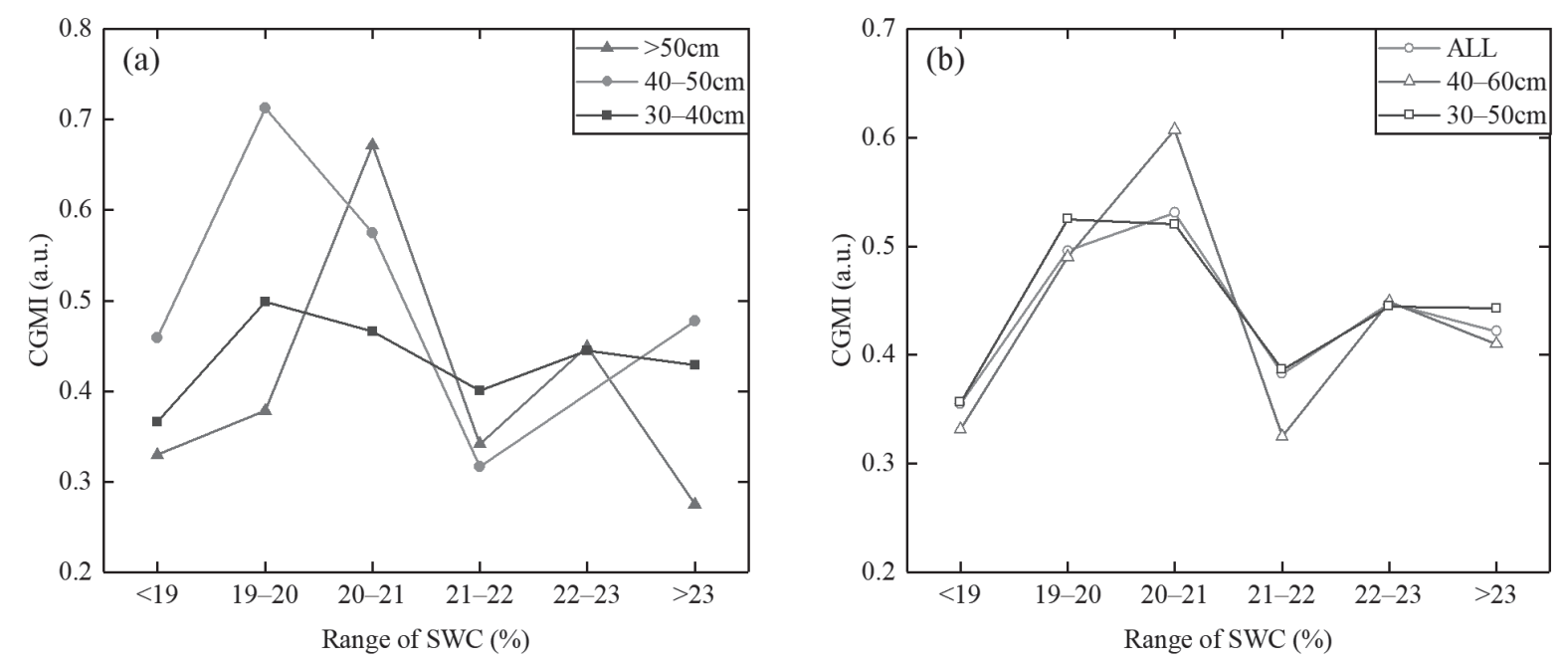

Fig. 9. Response relationship between the CGMI and SWC for different TCS ranges. 
of traditional methods of acquiring information through sampling. In addition, the CG, SWC, and TCS of the entire study area were fully determined. The use of UAV remote sensing in research has increased in recent years. The technology has become more mature and has been gradually applied in precision agriculture and smart agriculture [52]. In this study, the CG detection model based on a combination of multiple vegetation indexes and the extreme learning machine algorithm was used, which is a new method that overcomes the uncertainty of the traditional UAV single-parameter model [53]. The CGMI of the winter wheat in the study area obtained via UAV remote sensing (Fig. 4) is useful for monitoring the agricultural planting and agricultural management in the reclaimed area in real time.

In addition, we applied GPR, a near-ground microwave remote sensing technique, to the identification of the soil-fly ash layers in a reclaimed area. This method is currently mostly used in the detection of road thickness and asphalt layers [54]. In this study, the information about the TCS was accurately obtained through preprocessing of the GPR data. Then, the results of the GPR were rechecked and calibrated using the compactness data. The advantage of the GPR method is that it can be used to quickly and non-destructively obtain information about the underground structures and to further analyze the response relationships between the TCS, SWC, and CGMI. Moreover, this method effectively solves the shortcomings of the fuzzy underground structures and uncertain levels encountered in previous studies, and it can gradually be extended to farmland soil thickness detection based on this study. In recent years, GPR has gradually been applied to the non-destructive and rapid acquisition of the SWC [28, 55]. Therefore, some research has been conducted on the acquisition of the water content of the cultivated layer while studying the identification of the TCS. The Hilbert transform was used to obtain the AEA value of the first positive half-cycle signal of the GPR data. The GWR model was used to establish an SWC inversion model, which greatly improves the accuracy of the SWC inversion. As the GPR technique is being increasingly applied in large-scale hydrology studies, the multi-factor GWR analysis method adopted in this study will help to improve the accuracy and scientific nature of the SWC acquisition for complex soil structures. It is very important to consider the influences of multiple factors on the moisture accumulation in future research.

The biggest problem with the filling reclamation method is the poor water retention of the covering soil, which results in the loss of nutrients and the fertility of the plough soil. Numerous scholars have also proposed many methods to solve this problem, such as hybrid filling and remediation techniques and mixing waterretaining materials with the soil [56]. However, most of these methods are in the indoor test stage and are expensive to implement. The multi-source remote sensing data acquisition method proposed in this article has reference significance for the evaluation of the restoration effect of reclamation methods in future. In this study, we mainly relied on UAV and GPR techniques to analyze the impact of filling reclamation engineering measures on the soil water retention and CG. The effects of the soil nutrients and root distribution on the CG and SWC were not considered. The soil nutrient index, as an essential index for fertility evaluation, has an important influence on the CG and determines the CG to a large extent [57]. Therefore, the relationship between the soil nutrients and TCS in reclaimed areas will be the focus of our future work. The roots of the crops in the soil also have a certain impact on the water content in the plough layer [58]. Therefore, it is necessary to continue to quantify the degree of influence of the roots on the accumulation of water in future studies. These factors need to be incorporated into the multi-factor model in order to ensure that the GPR detection method has a strong universal applicability in future. In this study, the influence was only studied from three aspects (TCS, SWC, and CGMI). Understanding the deeper relationships will require more experiments, for example, the analysis of the internal potential influencing factors through structural equation modeling. Therefore, we advocate conducting more field research to promote the important applications of multi-source remote sensing technology in monitoring the effects of reclamation methods in future.

\section{Conclusions}

In this study, the multi-source remote sensing technique was coupled with ground penetrating radar and unmanned aerial vehicle remote sensing to obtain the winter wheat crop growth, soil water content, and thickness of the covering soil in the study area. The response relationships between the TCS and the SWC and the comprehensive growth monitoring index in a reclaimed area filled with fly ash were analyzed. Through analysis of the response relationships between the TCS, SWC, and CGMI, we found that the CG improves as the TCS increases. Moreover, considering the large economic costs and the limited available soil sources, the optimal TCS is $40-50 \mathrm{~cm}$. In addition, we also analyzed the relationship between the SWC and CGMI, and the results show that the best SWC is $19 \%-21 \%$ in the reclaimed area. This study systematically explained the relationships between the TCS, SWC, and CGMI based on data acquired using a multi-source remote sensing platform. The optimal TCS for the fly ash filling reclamation method was determined. In summary, the fast and non-destructive advantages of multi-source remote sensing are a huge improvement on traditional methods. The results of this study will help improve the application of multi-source remote sensing to the rapid evaluation of the restoration effect and farmland CG monitoring in reclaimed areas. 


\section{Acknowledgments}

This study was supported by Natural resources science and technology project of Anhui Province (2020-K-8), National Key R\&D Program of China (2020YFC1908601), and Technology R\&D Project of Huaibei Mining Group (2020-113). The authors are thankful for the assistance in field data collection from Jun Ma, Xianglin Dong and Xiangping Wei.

\section{Conflict of Interest}

The authors declare no conflict of interest.

\section{References}

1. DONG J., MENG L., BIAN Z., FANG A. Investigating the Characteristics, Evolution and Restoration Modes of Mining Area Ecosystems, Polish Journal of Environmental Studies, 28 (5), 3539, 2019.

2. XIA K., XIA S.S., SHEN Q., YANG B., SONG Q., XU Y.F., ZHANG S.W., ZHOU X., ZHOU Y. Moisture spectral characteristics and hyperspectral inversion of fly ash-filled reconstructed soil, Spectrochim Acta A, 253, 119590, 2021.

3. ŠOFRANKO M., VéGSöOVá O., KALáSZ T., SULOVEC V., BECA J., ŠUVER M. Effect of Reclamation on an Environment Impaired by Mining Activity: A Case Study, Polish Journal of Environmental Studies, 29 (5), 3329, 2020.

4. BROSENS L., CAMPFORTS B., ROBINET J., VANACKER V., OPFERGELT S., AMEIJEIRASMARINO Y., MINELLA J.P.G., GOVERS G. Slope Gradient Controls Soil Thickness and Chemical Weathering in Subtropical Brazil: Understanding Rates and Timescales of Regional Soilscape Evolution Through a Combination of Field Data and Modeling, Journal of Geophysical Research-Earth Surface, 125 (6), 5321, 2020.

5. WU Z.Y., XIA T.X., NIE J.L., CUI F. The shallow strata structure and soil water content in a coal mining subsidence area detected by GPR and borehole data, Environmental Earth Sciences, 79 (22), 2020.

6. KERR Y.H., WALDTEUFEL P., WIGNERON J.P., DELWART S., CABOT F., BOUTIN J., ESCORIHUELA M.J., FONT J., REUL N., GRUHIER C., JUGLEA S.E., DRINKWATER M.R., HAHNE A., MARTIN-NEIRA M., MECKLENBURG S. The SMOS Mission: New Tool for Monitoring Key Elements of the Global Water Cycle, Proceedings of The Ieee, 98 (5), 666, 2010.

7. WANG L.J., ZHANG G.M., WANG Z.Y., LIU J.G., SHANG J.L., LIANG L. Bibliometric Analysis of Remote Sensing Research Trend in Crop Growth Monitoring: A Case Study in China, Remote Sensing, 11 (7), 809, 2019.

8. ZHANG S.M., ZHAO G.X., LANG K., SU B.W., CHEN X.N., XI X., ZHANG H.B. Integrated Satellite, Unmanned Aerial Vehicle (UAV) and Ground Inversion of the SPAD of Winter Wheat in the Reviving Stage, Sensors, 19 (7), 1485,2019

9. DEHKORDI R.H., DENIS A., FOUCHE J., BURGEON V., CORNELIS J.T., TYCHON B., GOMEZ E.P., MEERSMANS J. Remotely-sensed assessment of the impact of century-old biochar on chicory crop growth using high-resolution UAV-based imagery, International Journal of Applied Earth Observation and Geoinformation, 91, 102147, 2020.

10. FU Z.P., JIANG J., GAO Y., KRIENKE B., WANG M., ZHONG K.T., CAO Q., TIAN Y.C., ZHU Y., CAO W.X., LIU X.J. Wheat Growth Monitoring and Yield Estimation based on Multi-Rotor Unmanned Aerial Vehicle, Remote Sensing, 12 (3), 508, 2020.

11. HASSAN M.A., YANG M.J., RASHEED A., YANG G.J., REYNOLDS M., XIA X.C., XIAO Y.G., HE Z.H. A rapid monitoring of NDVI across the wheat growth cycle for grain yield prediction using a multi-spectral UAV platform, Plant Science, 282, 95, 2019.

12. KOGANTI T., GHANE E., MARTINEZ L.R., IVERSEN B.V., ALLRED B.J. Mapping of Agricultural Subsurface Drainage Systems Using Unmanned Aerial Vehicle Imagery and Ground Penetrating Radar, Sensors, 21 (8), $2800,2021$.

13. MOREY R.M. Continuous subsurface profiling by impulse radar. Proceedings, Engineering Foundations Conference on Subsurface Exploration for Underground Excavations and Heavy Construction, Henniker, New Hampshire, 213, 1974.

14. LIU C., LIU G., LI H.R., WANG X.K., CHEN H., DAN C.X., SHEN E.S., SHU C.B. Using ground-penetrating radar to investigate the thickness of mollic epipedons developed from loessial parent material, Soil \& Tillage Research, 212, 105047, 2021.

15. MARECOS V., SOLLA M., FONTUL S., ANTUNES V. Assessing the pavement subgrade by combining different non-destructive methods, Construction and Building Materials, 135, 76, 2017.

16. LUO G., CAO Y., XU H., YANG G., WANG S., HUANG Y., BAI Z. Detection of soil physical properties of reclaimed land in open-pit mining area: feasibility of application of ground penetrating radar, Environmental Monitoring and Assessment, 193 (7), 392, 2021.

17. CHENG Q., YE H.C., DONG X.L., CUI H.B., YI Q.T., XU Y.F., SUN L.Y., ZHANG S.W. Inversion of reclaimed soil moisture based on spectrum analysis of ground penetrating radar, Transactions of the Chinese Society of Agricultural Engineering, 37 (6), 108, 2021.

18. TOPP G.C., DAVIS J.L., ANNAN A.P. Electromagnetic determination of soil water content: Measurements in coaxial transmission lines, Water Resources Research, 16 (3), 574, 1980.

19. KNOLL M.D., KNIGHT R., BROWN E. Can accurate estimates of permeability be obtained from measurements of dielectric properties?, 8th EEGS Symposium on the Application of Geophysics to Engineering and Environmental Problems, European Association of Geoscientists \& Engineers, 25, 1995.

20. CAO Q., SONG X.D., WU H.Y., GAO L., LIU F., YANG S.H., ZHANG G.L. Mapping the response of volumetric soil water content to an intense rainfall event at the field scale using GPR, Journal of Hydrology, 583, 124605, 2020.

21. PETTINELli E., VANNARONI G., DI PASQUO B., MATTEI E., DI MATTEO A., DE SANTIS A., ANNAN P.A. Correlation between near-surface electromagnetic soil parameters and early-time GPR signals: An experimental study, Geophysics, 72 (2), 25, 2007.

22. ALGEO J., VAN DAM R.L., SLATER L. Early-Time GPR: A Method to Monitor Spatial Variations in Soil Water Content during Irrigation in Clay Soils, Vadose Zone Journal, 15 (11), 2016. 
23. LIU X., DONG X., LESKOVAR D.I. Ground penetrating radar for underground sensing in agriculture: a review, International Agrophysics, 30 (4), 533, 2016.

24. WEI P.F., XU X.G., LI Z.Y., YANG G.J., LI Z.H., FENG H.K., CHEN G., FAN L.L., WANG Y.L., LIU S.B. Remote sensing estimation of nitrogen content in summer maize leaves based on multispectral images of UAV, Transactions of the Chinese Society of Agricultural Engineering, 35 (8), 126, 2019.

25. TOSTI F., CIAMPOLI L.B., CALVI A., ALANI A.M., BENEDETTO A. An investigation into the railway ballast dielectric properties using different GPR antennas and frequency systems, Ndt \& E International, 93, 131, 2018.

26. STEVENSON P.R. Microearthquakes at Flathead Lake, Montana: A study using automatic earthquake processing, Bulletin of the Seismological Society of America, 66 (1), 61, 1976.

27. LIU X.M., ZHAO J.J., WANG Y.M., PENG P.A. Automatic picking of microseismic events p-wave arrivals based on improved method of STA/LTA, Journal of Northeastern University. Natural Science, 38 (5), 740, 2017.

28. ANBAZHAGAN P., BITTELLI M., PALLEPATI R.R., MAHAJAN P. Comparison of soil water content estimation equations using ground penetrating radar, Journal of Hydrology, 588, 125039, 2020.

29. CUI X.H., ZHANG Z., GUO L., LIU X.B., QUAN Z.X., CAO X., CHEN X.H. The Root-Soil Water Relationship Is Spatially Anisotropic in Shrub-Encroached Grassland in North China: Evidence from GPR Investigation, Remote Sensing, 13 (6), 1137, 2021.

30. BENEDETTO A., TOSTI F., CIAMPOLI L.B., D'AMICO F. An overview of ground-penetrating radar signal processing techniques for road inspections, Signal Process, 132, 201, 2017.

31. SHAFIAN S., RAJAN N., SCHNELL R., BAGAVATHIANNAN M., VALASEK J., SHI Y.Y., OLSENHOLLER J. Unmanned aerial systems-based remote sensing for monitoring sorghum growth and development, Plos One, 13 (5), e0196605, 2018.

32. LIU Z., WAN W., HUANG J., HAN Y., WANG J. Progress on key parameters inversion of crop growth based on unmanned aerial vehicle remote sensing, Transactions of the Chinese Society of Agricultural Engineering, 34 (24), 60, 2018

33. ZHOU X.F., HUANG W.J., KONG W.P., YE H.C., LUO J.H., CHEN P.F. Remote estimation of canopy nitrogen content in winter wheat using airborne hyperspectral reflectance measurements, Advances in Space Research, 58 (9), 1627, 2016.

34. ISSA S., DAHY B., SALEOUS N., KSIKSI T. Carbon stock assessment of date palm using remote sensing coupled with field-based measurements in Abu Dhabi (United Arab Emirates), International Journal of Remote Sensing, 40 (19), 7561, 2019.

35. JIANG Z.Y., HUETE A.R., DIDAN K., MIURA T. Development of a two-band enhanced vegetation index without a blue band, Remote Sensing of Environment, 112 (10), 3833, 2008.

36. OSCO L.P., MARCATO J., RAMOS A.P.M., FURUYA D.E.G., SANTANA D.C., TEODORO L.P.R., GONCALVES W.N., BAIO F.H.R., PISTORI H., DA SILVA C.A., TEODORO P.E. Leaf Nitrogen Concentration and Plant Height Prediction for Maize Using UAV-Based Multispectral Imagery and Machine Learning Techniques, Remote Sensing, 12 (19), 3237, 2020.
37. QI H.X., ZHU B.Y., WU Z.Y., LIANG Y., LI J.W., WANG L.D., CHEN T.T., LAN Y.B., ZHANG L. Estimation of Peanut Leaf Area Index from Unmanned Aerial Vehicle Multispectral Images, Sensors, 20 (23), 2020.

38. DASH J., JEGANATHAN C., ATKINSON P.M. The use of MERIS Terrestrial Chlorophyll Index to study spatiotemporal variation in vegetation phenology over India, Remote Sensing of Environment, 114 (7), 1388, 2010.

39. FU Y.Y., YANG G.J., SONG X.Y., LI Z.H., XU X.G., FENG H.K., ZHAO C.J. Improved Estimation of Winter Wheat Aboveground Biomass Using Multiscale Textures Extracted from UAV-Based Digital Images and Hyperspectral Feature Analysis, Remote Sensing, 13 (4), 581, 2021.

40. ZHAO Y., ZHENG W., XIAO W., ZHANG S., LV X., ZHANG J. Rapid monitoring of reclaimed farmland effects in coal mining subsidence area using a multi-spectral UAV platform, Environmental Monitoring and Assessment, 192 (7), 474, 2020.

41. LIU J.G., PATTEY E., MILLER J.R., MCNAIRN H., SMITH A., HU B.X. Estimating crop stresses, aboveground dry biomass and yield of corn using multitemporal optical data combined with a radiation use efficiency model, Remote Sensing of Environment, 114 (6), 1167, 2010.

42. LI X.R., YANG C.H., HUANG W.J., TANG J., TIAN Y.Q., ZHANG Q. Identification of Cotton Root Rot by Multifeature Selection from Sentinel-2 Images Using Random Forest, Remote Sensing, 12 (21), 3504, 2020.

43. TAO Z., GE L.L., CHEN H. Nnon-negative variable weight combination forecasting method based on sliding window, Control and Decision, 35 (6), 1446, 2020.

44. LU Q., WANG Y., LI H. GPR attribute analysis for the detection of LNAPL contaminated soils, IOP Conference Series: Earth and Environmental Science, 660 (1), 12033, 2021.

45. DI MATTEO A., PETTINELli E., SLOB E. EarlyTime GPR Signal Attributes to Estimate Soil Dielectric Permittivity: A Theoretical Study, Ieee Transactions on Geoscience and Remote Sensing, 51 (3), 1643, 2013.

46. CHEN H.Y., ZHAO G.X., CHEN J.C., WANG R.Y., GAO M.X. Remote sensing inversion of saline soil salinity based on modified vegetation index in estuary area of Yellow River, Transactions of the Chinese Society of Agricultural Engineering, 31 (5), 107, 2015.

47. JIANG H.L., YANG H., CHEN X.P., WANG S.D., LI X.K., LIU K., CEN Y. Research on Accuracy and Stability of Inversing Vegetation Chlorophyll Content by Spectral Index Method, Spectroscopy and Spectral Analysis, 35 (4), 975, 2015.

48. GUO L., LIN H. Critical Zone Research and Observatories: Current Status and Future Perspectives, Vadose Zone Journal, 15 (9), 2016.

49. SONG M.Z., LIN S.L., TAKAHASHI F. Coal fly ash amendment to mitigate soil water evaporation in arid/ semi-arid area: An approach using simple drying focusing on sieve size and temperature, Resources Conservation and Recycling, 156, 104726, 2020.

50. XUAN L., WENKAI L., HEBING Z., HAIPENG N. Comprehensive Landscape Ecology Stability Assessment of a Coal Gangue Backfi 11 Reclamation Area, Polish Journal of Environmental Studies, 25 (3), 1305, 2016.

51. LIU L., GUDMUNDSSON L., HAUSER M., QIN D., LI S., SENEVIRATNE S.I. Soil moisture dominates dryness stress on ecosystem production globally, Nature Communications, 11 (1), 4892, 2020. 
52. OLSON D., ANDERSON J. Review on unmanned aerial vehicles, remote sensors, imagery processing, and their applications in agriculture, Agronomy Journal, 113 (2), 971, 2021.

53. DEO R.C., SAHIN M., ADAMOWSKI J.F., MI J.C. Universally deployable extreme learning machines integrated with remotely sensed MODIS satellite predictors over Australia to forecast global solar radiation: A new approach, Renewable \& Sustainable Energy Reviews, 104, 235, 2019.

54. WANG S.Q., ZHAO S., AL-QADI I.L. Continuous real-time monitoring of flexible pavement layer density and thickness using ground penetrating radar, Ndt \& E International, 100, 48-54, 2018.

55. IWASAKI K., TAMURA M., SATO H., MASAKA K., OKA D., YAMAKAWA Y., KOSUGI K.i. Application of
Ground-Penetrating Radar and a Combined PenetrometerMoisture Probe for Evaluating Spatial Distribution of Soil Moisture and Soil Hardness in Coastal and Inland Windbreaks, Geosciences, 10 (6), 238, 2020.

56. DU T., WANG D.M., BAI Y.J., ZHANG Z.Z. Optimizing the formulation of coal gangue planting substrate using wastes: The sustainability of coal mine ecological restoration, Ecological Engineering, 143, 105669, 2020.

57. PURUCKER T., STEINKE K. Soybean seeding rate and fertilizer effects on growth, partitioning, and yield, Agronomy Journal, 112 (3), 2288-2301, 2020.

58. GUO L., MOUNT G.J., HUDSON S., LIN H., LEVIA D. Pairing geophysical techniques improves understanding of the near-surface Critical Zone: Visualization of preferential routing of stemflow along coarse roots, Geoderma, 357, 113953, 2020. 